\title{
ULRICH BECK (1944-2015), METODOLOGISEN KOSMOPOLITANISMIN SOSIOLOGI
}

Lähes kolmekymmentä vuotta sitten, lauantaina 26. huhtikuuta 1986 tapahtui ydinvoimalaonnettomuus Ukrainan sosialistisessa neuvostotasavallassa Tšernobylin Vladimir Leninin mukaan nimetyssä ydinvoimalaitoksessa lähellä Pripjatin kaupunkia, Pohjois-Ukrainassa. Ydinvoimalaonnettomuuden INESyksikkö oli INES 7 (vakavin onnettomuus). Radioaktiivisia aineita levisi tuulen mukana usean päivän ajan monen maan alueelle, myös Suomeen. Pitoisuudet olivat suurimmillaan 28.4. illalla, jolloin ilmasta mitattiin yli 30 radioaktiivista ainetta. Tšernobylin laskeuma lisää Säteilyturvakeskus STUKin mukaan vielä nykyäänkin suomalaisten säteilyannosta, mutta määrä on vain sadasosa vuosittaisesta keskimääräisestä 3,7 millisievertin annoksestamme.

Ulrich Beck päiväsi pääteoksensa Risikogesellschaft: Auf dem Weg in eine andere Moderne (Beck 1986) juuri ennen Tšernobylin ydinvoimalaonnettomuutta Bambergissa, Baijerissa, huhtikuulle 1986, mutta ennen kuin kirja ehti ilmestyä, hän lisäsi alkuun saatesanat, joissa hän käsitteli tuoreeltaan Tšernobylin ydinvoimalaonnettomuutta. Onni onnettomuudessa, Beckin riskiyhteiskunta tuli heti tunnetuksi, vaikka lopullinen läpimurto kansainvälisessä sosiologiyhteisössä tapahtui vasta sen jälkeen kun kirja ilmestyi englanniksi vuonna 1992 ja sittemmin yli kolmellakymmenellä kielellä (esim. koreaksi, ruotsiksi ja tanskaksi 1997, japaniksi ja espanjaksi 1998, italiaksi ja venäjäksi 2000, ranskaksi 2001, puolaksi 2002, viroksi 2005, turkiksi 2011).

Tšernobylin ydinvoimalaonnettomuudesta Beck kirjoitti:
Kaikki kärsimys, hätä, kaikki väkivalta, jota ihmiset ovat ihmisille aiheuttaneet, koski aiemmin 'toisten' kategoriaa - juutalaisia, mustia, naisia, turvapaikanhakijoita, toisinajattelijoita, kommunisteja jne. [...] Näin on edelleen eikä ole enää Tšernobylin jälkeen. Se on 'toisten' loppu, kaikkien kehittämiemme etäisyydenottomahdollisuuksien loppu, minkä olemme saaneet kokea ydinsaasteiden myötä. Hätä ei salli enää atomiaikakauden vaarojen poissulkemista.

Yleisemmällä tasolla Beckin riskiyhteiskunnassa on kyse sellaisista riskeistä, jotka saavat samalla metaforiset mitat: riskit eivät ole enää paikallisia, vaan ne ylittävät kaupunginosien rajat, alueelliset rajat, valtiolliset rajat samoin kuin luokkarajat, eikä niitä voi päästä mihinkään pakoon.

Kirjassa käsitellään Tšernobylin jälkeistä aikaa uudenlaisena sosiaalisten riskien yhteiskunnallisena tilanteena - jakautumisena -, muun muassa yhteiskuntarakenteen, sukupuolten välisten ristiriitojen, tieteen ja tekniikan sekä politiikan kannalta. Tieteen ja teknologian edistys ja kehitys teollisuusyhteiskunnassa ovat muuttuneet siunauksellisista kirouksiksi.

Beckin lähtökohtana oli "aikalaisdiagnostinen" (Noro 2004) moderniteettiteoria; yleinen teesi on, että olemme siirtyneet toiseen moderniin, klassisesta teollisuusyhteiskunnasta riskiyhteiskuntaan, yksinkertaisesta modernisaatiosta refleksiivisen modernisaatioon. "Toinen moderni" (refleksiivinen modernisaatio) merkitsi vapautumista ensimmäisen modernin (yksinkertainen modernisaatio) ryhmäsidonnaisista perinteistä ja varmuudesta yksilölliseen vapauteen ja epävarmuuteen sekä 
yksilöllisiin riskeihin, mihin sisältyi kuitenkin Beckin ajattelulle tyypillisesti optimistinen vapautumisen mahdollisuus.

Refleksiivisen modernisaation lisäksi monet muutkin Beckin ideat, joita hän kehitti myöhemmin pidemmälle, olivat jo Riskiybteiskunnassa itumuodossa. Ja riskiyhteiskunnan käsitteen lisäksi Beck sepitti useita muita käsitteitä ja teemoja, kuten kosmopolitianismi, maailmanriskiyhteiskunta, viimeksi "maailman metamorfoosi". Leimallista näille kaikille on vissi ohjelmallisuus.

Sosiologisesti keskeinen teema Riskiybteiskunnassa on yksilöllistyminen, ja se on yksi tärkeimmistä keskustelua virittäneistä teoksista 1980-luvulla. Aiheen kehittelyä jatkoi erityisesti Beckin, Anthony Giddensin ja Scott Lashin keskusteluteos Nykyajan jäljillä: Refleksiivinen modernisaatio (Beck, Giddens \& Lash 1995). Yksilöllistymisteesi on sittemmin herättänyt myös paljon kriittistä keskustelua erityisesti uudessa luokkatutkimuksessa.

Itse asiassa yksilöllistymistä Riskiyhteiskunnassa käsittelevä keskeinen luku "Jenseits von Klass und Sicht" on alun perin jo Beckin 80-luvun alussa kirjoituksessa "Jenseits von Klasse und Stand?" (Beck 1983, 35-74) kehittelemä analyysi. Beck lähtee sodanjälkeisen Länsi-Saksan hyvinvointivaltion kehityksestä, joka on johtanut "luokkien ja kerrostumien tuolle puolen", kuten hän kirjoittaa, - juuri siitä on kyse yksilöllistymiskehityksessä, luokkien ja kerrostumien 'tuolla puolen' tapahtuvasta kehityksestä. Beck toteaa kyllä ensiksi, että LänsiSaksassa sosiaalinen eriarvoisuus on pysynyt verraten vakiona toisen maailmansodan jälkeen; mitään suuria mullistuksia suuntaan tai toiseen ei ole tapahtunut. Eriarvoisuus on saanut uusia yksilöllisiä muotoja, kuten "uusköyhyys". Mutta toisaalta on tapahtunut merkittävä muutos: kaikille on taloudellisen kasvun ja hyvinvointivaltion kehityksen myötä siunaantunut"kollektiivisesti enemmän": enemmän tuloja, koulutusta, liikkuvuutta, oikeutta, tiedettä - ja viimein, muttei vähiten: massakulutusta. Kyseessä on niin sanottu 'hissiefekti', hissivaikutus: kaikki ovat ikään kuin nousseet kerroksen ylemmäs. Näin siis Saksassa, ja käsittääkseni se pätee pitkälti myös Suomeen, mutta Beck toteaa, että Iso-Britanniassa ja Ranskassa näin ei ole laita.

Riskit hallitsevat elämäämme uudella tavalla yksilöllisesti. Ne tunkeutuvat arkielämäämme olennaisena osana modernia maailmaa, joka on vapautunut traditioista ja tavoista. Elämästämme on siten tullut "refleksiivistä", sellaista, jota on pohdittava ja punnittava alituiseen. Siitä hyvä esimerkki ovat modernit"suhteet" ja avioliitto, josta on tullut kahdenvälinen sopimus ja jatkuvan reflektoinnin aihe. Avioliittoa solmiessaan käytännöllisesti katsoen kaikki tunnustavat, että avioeroluvut ovat korkeat, ja tästä ollaan tietoisia avioitumispäätöksessä. Näitä asioita Beck käsitteli yhdessä vaimonsa, tunnetun perhesosiologi Elisabeth Beck-Gernsheimin kanssa teoksissa Das ganz normale Chaos der Liebe (Beck \& Beck-Gernsheim1990) ja Fernliebe: Lebensformen im globalen Zeitalter (Beck \& Beck-Gernsheim 2011).

Beck (1999c, 43-49) oli 80-luvulla sosiologiassa myös ensimmäisiä, jotka käsittelivät globalisaatiota uudella tavalla. Hän tekee tärkeän eron globaalisuuden, globalismin ja globalisaation välillä: globaalisuus (elämme maailmanyhteiskunnassa; refleksiivisyys, muutettavuus), globalismi (ideologia maailmanmarkkinoiden ylivertaisuudesta sinänsä), globalisaatio (prosessi jonka alaisena kansallisvaltiot ovat markkinoiden vaikutuksesta). Ensiksi mainittu eli globaalisuus on Beckin mukaan nykyisin peruuttamaton tilanne. Globalismi sen sijaan on neoliberalistinen oppi, maailmanmarkkinoiden herruuden ideologia. Globalisaatio puolestaan on prosessi, jonka seurausvaikutuksien piiriin kaikki kansallisvaltiot ovat joutuneet ja jonka seurauksena ne samalla uudella tavalla verkostoituvat. Se on eräänlainen kansallisvaltioiden eroosio, joka - jälleen - sisältää Beckin mielestä myös muutoksen mahdollisuuden.

Beck kritisoi yhteiskuntatieteitä "metodologisesta nationalismista", jossa kansakunta/ maa on "luonnollinen" tutkimusyksikkö. Kan- 
sallinen konteksti on liian kapea niiden tekijöiden ymmärtämiseksi, jotka liikuttavat elämäämme globaalilla aikakaudella. Vastaavasti EU:n tulisi olla ylikansallinen projekti, eikä vain kansakuntien kokoelma. Teoksessaan Der kosmopolitische Blick (Beck 2004) Beck esitti, että yhteiskunnan kasvava globaali luonne johtaisi siihen, että kansallisen suvereniteetin ajattelu väistyisi kosmopolitanismin tieltä. ****

Runsaat sata vuotta sitten Max Weber tähdensi ohjelmallisesti kuuluisassa kirjoituksessaan Die "Objektivität" sozialwissenschaftlicher und sozialpolitischer Erkenntnis (1904), että sosiaalitieteet kuuluvat historiallisiin kulttuuritieteisiin, "jotka on tuomittu ikuiseen nuoruuteen" ja "jotka kulttuurin ikuisesti etenevä virta johtaa alati uusiin ongelmanasetteluihin". Niiden "tehtävänluonteeseen kuuluu kaikkien ideaalityyppisten konstruktioiden katoavaisuus, mutta samalla uusien välttämättömyys" (Weber 1968 [1904], 206). Sosiaalitieteiden käsitteet ovat sidottuja aikaansa; ne vanhenevat. Niiden "ajatteluaparaatin" on siis uudistuttava alituisesti, eikä sosiaalitieteissä voida koskaan saavuttaa lopullista synteesiä: "Sosiaalitieteissä laajakantoisimmat edistysaskeleet liittyvät asiallisesti kulttuuristen ongelmien muutoksiin ja ne pukeutuvat käsitteenmuodostuksen kritiikin muotoon"(Weber 1968 [1904], 208).

Sittemmin ennen muuta Beck on jatkanut weberiläistä keskustelua sosiologian arkkikäsitteiden antikvaarisuudesta (esim. Beck 1999b). "Toisen modernin" sosiologiassa tarvitaan uusia käsitteitä, jotta voisimme käsittää, missä olemme ja mihin olemme menossa. Vain uusilla käsitteillä voidaan tavoittaa nykyisyydestä tulevaisuus. Beck (1999b) on kutsunut vanhoja ja jäykkiä käsitteitä zombi-käsitteiksi, kuolleiksi käsitteiksi, jotka kuitenkin elävät ja joilla hahmotamme maailmaa. Sellaisia ovat työ, kansakunta, luokka ja perhe, sellaisina kuin ne on viime vuosisadalla ymmärretty js vielä nykyäänkin ymmärretään. Weberin hengessä Beck puhuu "zombikategorioista (ja zombi-instituutioista)", jotka ovat "perustavia esteitä aikamme dyna- miikan ja haasteiden ymmärtämiseksi” (Beck 1999b, 257). Pitäessämme kiinni moderneista, mutta jo vanhentuneista kategorioista uusinnamme vanhaa ajatusjärjestelmää ja käsitystä yhteiskunnasta. Olemme kiinni vanhassa yhteiskunnassa. Beckin esimerkkinä oli täystyöllisyys tai pikemminkin sen loppu. En palaa tässä siihen eli teesiin niin sanotusta "työyhteiskunnan systeeminmuutoksesta" (Beck 1986), josta käytiin paljon keskustelua vallankin 1980- ja -90-luvuilla (ks. Rahkonen 1996). ***

Beck oli vannoutunut Euroopan Unionin kannattaja ja julkaisi aiheeseen liittyen useita kirjoituksia, mm. kirjan Das deutsche Europa (2012). Hän kritisoi erityisesti Saksan EU-politiikkaa. Thomas Mannin kuuluisaan lausahdukseen 1950-luvulta viitaten Beck totesi, että Euroopan integraation tehtävänä tulisi olla luoda "eurooppalainen Saksa”, ei"saksalaista Eurooppaa", jollainen kuitenkin eurokriisin jälkiseurauksena on syntynyt. Ja liitokansleri Angela Merkelistä on tullut de facto "EU:n presidentti". Beck kutsuikin häntä "Merkiavelliksi". Yhdessä monien eurooppalaisten intellektuellien (Jürgen Habermas, Jacques Delors, Bruno Latour, Zygmunt Bauman, Etienne Balibar, Anthony Giddens, Agnes Heller, Mary Kaldor, Adam Michnik, Edgar Morin, Alain Touraine, Michel Wieviorka ym.) kanssa hän - aloitteentekijänä - julkaisi vuoden 2014 Euroopan parlamentin vaalien edellä vetoomuksen Vote for Europe!/ Wäblt Europa!, jossa kehotettiin ihmisiä äänestämään "toisenlaisen Euroopan" puolesta. ***

Beckin riskiyhteiskunnan teoria rantautui Suomeen verraten pian ilmestymisensä jälkeen. Ansio oli ennen muuta Risto Eräsaaren, joka tuolloinkin seurasi tarkkaavaisesti saksalaista keskustelua. Eräsaari järjesti Jyväskylän yliopistossa aiheesta "Riskiyhteiskunnan sosiologia" -symposiumin vuonna 1988 , ja sen puheenvuorot julkaistiin Sosiologia-lehden numerossa 1/89, jossa Arto Noro kirjoitti yksilöllistyvästä palkkatyöläisyhteiskunnasta ja posttraditionaaleista yhteisöistä, Risto Eräsaa- 
ri modernisoitumisriskeistä, Keijo Rahkonen työyhteiskunnan tulevaisuudesta, Riitta Jallinoja perheen modernisoitumisesta ja Risto Heiskala sukupuolesta modernissa.

Beckin pääteosta Risikogesellschaft ei ole suomennettu, mutta sen sijaan kaksi muuta teosta: Riskiybteiskunnan vastamyrkyt: Organisoitu vastuuttomuus (Beck 1990) ja Mitä globalisaatio on? Virbekäsityksiä ja poliittisia vastauksia (Beck 1999a) sekä Nykyajan jäljillä: Refleksiivinen modernisaatio (Beck, Giddens \& Lash 1995). Lisäksi Beckiltä on käännetty pari artikkelia, joista toinen - "Työyhteiskunnan tuolle puolen" - ilmestyi Janus-lehdessä (Beck 1999b), toinen - "Kosmopoliittinen perspektiivi: Toisen modernin sosiologiasta" - $t \mathcal{E} e$ :ssä (Beck 1999c).

Beck vieraili Suomessa useammankin kerran, kerran myös vaimonsa Elisabethin kanssa. He olivat intohimoisia suomalaisen saunan ystäviä, jotka saunoivat niin Helsingissä kerrostalosaunassa kuin savusaunassa Höytiäisen rannalla. Beck vihittiin Jyväskylän yliopiston kunniatohtoriksi vuonna 1996.

****

Saksalainen sosiologi Ulrich Beck kuoli uudenvuoden päivänä 1. tammikuuta 2015 äkillisesti sydäninfarktiin kotikaupungissaan Münchenissä. Hän oli 70-vuotias, syntynyt 15.5.1944 silloisessa Stolpin kaupungissa, joka on nykyisin Slupsk Puolassa. Hänen perheensä pakeni toisen maailmansodan lopussa länteen, josta sittemmin tuli Länsi-Saksa, ja hän vietti lapsuutensa Hannoverissa. 1960-luvulla Beck opiskeli ensiksi oikeustiedettä Freiburgissa, mutta siirtyi pian opiskelemaan sosiologiaa Münchenin yliopistoon, missä hän väitteli 1972 aiheesta Objektivität und Normativität: Die TheoriePraxis-Debatte in der modernen deutschen und amerikanischen Soziologie (Beck 1974). Vuonna 1979 hänen habilitaatiotutkielmansa hyväksyttiin. Työskenneltyään professorina Münsterin (1979-81) and Bambergin (1981-92) yliopistossa hän palasi Münchenin yliopistoon, jonka professuurista hän jäi eläkkeelle vuonna 2009. Lisäksi hän oli vieraileva professori London
School of Economics and Political Science LSE:ssä (1997-2014) ja Maison des Sciences de l'Homme'ssa (2011-2014). Hän oli saksalaisen sosiologisen Soziale Welt -lehden toimittaja vuodesta 1980.

Ulrich Beckille myönnettiin Maailman sosiologiyhdistys ISA:n kokouksessa 2014 Lifetime Achievement Award - For Most Distinguished Contribution to Futures Research -tunnustuspalkinto.

Beck vitsaili ylpeänä usein siitä, että hän onnistui ajamaan menestyksellisesti Münchenissä erään aukion nimenmuutoksen Max Weber Platzista Max Weber Platziksi. Aukio oli vuonna 1915 nimetty merkittävän paikallisen virkamiehen, maistraatin jäsen Max Weberin mukaan, ei siis sosiologi Max Weberin mukaan, joka oli opettanut Münchenin yliopistossa ja kuoli Münchenissä 1920. Beckin onnistui vakuuttamaan kaupunginisät niin, että nykyään aukio on omistettu kahdelle merkittävälle Max Weberille.

Vuonna 2012 Beck sai huomattavan European Research Councilin (ERC) tutkimusrahoituksen projektiinsa "Methodological Cosmopolitanism: In the Laboratory of Climate Change”, joka jäi nyt häneltä ikävästi kesken, muiden jatkettavaksi. Beckin lähtökohtana oli epistemologinen ongelma: ilmastonmuutos on globaali ilmiö, mutta sosiologia operoi kansallisvaltion kategorioilla ja organisaatiomuodoilla, kas siinä "metodologinen nationalismi". Esimakua siitä mitä oli tulossa voi lukea Beckin artikkelista, joka ilmestyi tämän vuoden alussa,"Emancipatory catastrophism: What does it mean to climate change and risk society?" (Beck 2015). Itse asiassa sekin antaa Beckille tyypillisesti ambivalentisti aihetta optimismiin ympäristökatastrofien edessä: "Maailman metamorfoosi on globaalin riskin piilevä emansipatorinen sivuvaikutus".

Loppujen lopuksi Ulrich Beck varioi yhtä ja samaa teemaa läpi koko tuotantonsa.

- KEIJO RAHKONEN 


\section{ULRICH BECKIN KESKEINEN TUOTANTO}

1974 Objektivität und Normativität: Die Theorie-PraxisDebatte in der modernen deutschen und amerikanischen Soziologie. Hamburg: Rowohlt.

1980 (\&Michael Brater \& Hansjürgen Daheim) Soziologie der Arbeit und der Beruf: Grundlagen, Problemfelder, Forschungsergebnisse. Hamburg: Rowohlt.

1986 Risikogesellschaft:Auf dem Weg in eine andere Moderne. Frankfurt am Main: Suhrkamp.

1988 Gegengifte: Die organisierte Unverantwortlichkeit. Frankfurt am Main: Suhrkamp.

1990 (\& Elisabeth Beck-Gernsheim) Das ganz normale Chaos der Liebe. Frankfurt am Main: Suhrkamp.

1991 Politik in der Risikogesellschaft: Essays und Analysen. Frankfurt am Main: Suhrkamp.

1993 Die Erfindung des Politischen: Zu einer Theorie reflexiver Modernisierung. Frankfurt am Main: Suhrkamp. 1994 (\& Anthony Giddens \&Scott Lash) Reflexive Modernization. Cambridge: Polity Press.

1995 Die feindlose Demokratie. Stuttgart: Reklam.

1997 Was ist Globalisierung? Irrtümer des Globalismus Antworten auf Globalisierung. Frankfurt am Main: Suhrkamp.

1999 Schöne neue Arbeitswelt: Vision: Weltbürgergesellschaft.

Frankfurt am Main: Campus.

1999 World Risk Society. Cambridge: Polity Press.

\section{KIRJALLISUUS}

Beck, Ulrich (1983) Jenseits von Klasse und Stand? Teoksessa R. Kreckel (Hg.) Soziale Ungleichheiten. Sonderband 2 der Sozialen Welt. Göttingen: Schwartz, 35-74.

Beck, Ulrich (1990) Riskiyhteiskunnan vastamyrkyt: Organisoitu vastuuttomuus. Tampere: Vastapaino.

Beck,Ulrich (1992) Risk Society:Towards a New Modernity. London: Sage.

Beck,Ulrich (1995) Nykyajan jäljillä: Refleksiivinen modernisaatio. Tampere: Vastapaino.

Beck, Ulrich (Beck 1999a) Mitä globalisaatio on? Virhekäsityksiä ja poliittisia vastauksia. Tampere: Vastapaino.

Beck, Ulrich (1999b) Työyhteiskunnan tuolle puolen. Janus 7:3,257-266.

Beck, Ulrich (1999c) Kosmopoliittinen perspektiivi: Toisen modernin sosiologiasta. Tiede E edistys 24:3, 177-197.
2002 (\& Elisabeth Beck-Gernsheim) Individualization: Institutionalized Individualism and its Social and Political Consequences. London: Sage.

2002 Macht und Gegenmacht im globalen Zeitalter: Neue weltpolitische Ökonomie. Frankfurt am Main: Suhrkamp.

2002 Das Schweigen der Worter. Frankfurt am Main: Suhrkamp.

2004 Der kosmopolitische Blick oder: Krieg ist Frieden. Frankfurt am Main: Suhrkamp.

2004 (\&Edgar Grande) Das kosmopolitische Europa: Gesellschaft und Politik in der Zweiten Moderne. Frankfurt am Main: Suhrkamp.

2005 Was zur Wabl steht. Frankfurt am Main: Suhrkamp.

2007 Weltrisikogesellschaft: Auf der Suche nach der verlorenen Sicherheit. Suhrkamp, Frankfurt am Main.

2008 Der eigene Gott: Von der Friedensfähigkeit und dem Gewaltpotential der Religionen. Frankfurt am Main u. Leipzig: Verlag der Weltreligionen.

2008 Die Neuvermessung der Ungleichheit unter den Menschen: Soziologische Aufklärung im 21. Jahrbundert. Frankfurt am Main: Suhrkamp.

2010 Nacbricbten aus der Weltinnenpolitik. Berlin: Suhrkamp. 2011 (\& Elisabeth Beck-Gernsheim) Fernliebe: Lebensformen im globalen Zeitalter. Berlin: Suhrkamp.

2012 Das Deutsche Europa. Berlin: Suhrkamp.

Beck, Ulrich (2015) Emancipatory catastrophism: What does it mean to climate change and risk society? Current Sociology (2015) 63:1, 75-88.

Noro, Arto (2004) Aikalaisdiagnoosi: sosiologisen teorian kolmas lajityyppi? Teoksessa Keijo Rahkonen (toim.) Sosiologisia nykykeskusteluja. Helsinki: Gaudeamus, 19-39.

Rahkonen, Keijo (1996) Utopiat ja anti-utopiat: Kirjoituksia vuosituhannen päättyessä. Helsinki: Gaudeamus.

Riskiyhteiskunnan sosiologia -symposium. Sosiologia (1989) 26:1, 2-20.

Weber, Max (1968 [1904]) Die "Objektivität” sozialwissenschaftlicher und sozialpolitischer Erkenntnis. Teoksessa Max Weber (1968) Gesammelte Aufsätze zur Wissenschaftslehre. Hrsg. Johannes Winckelmann. Tübingen: J.C.B. Mohr (Paul Siebeck), 146-214. 